\title{
Family violence among mothers seen at the University of Ilorin Teaching Hospital, Ilorin, Nigeria
}

\section{B A Ayinmode, MB BS, FMCGP}

Department of General Medical Practice, University of Ilorin Teaching Hospital, Ilorin, Kwara State, Nigeria

M F Tunde-Ayinmode, MB BS, FMC Psych

Department of Behavioural Sciences, University of llorin Teaching Hospital, Ilorin, Kwara State, Nigeria

Objective. The attention given to family violence (FV) in primary medical care in Nigeria is still very insufficient in relation to its known adverse medical and psychosocial implications for women's health. The objective of this preliminary study was to assess the prevalence rate, correlates and effects of FV among mothers attending a primary care facility in Nigeria, with the aim of gaining an understanding of whether screening for $\mathrm{FV}$ in the primary care setting in Nigeria would be beneficial.

Methodology. A cross-sectional study of FV among 250 mothers attending the General Outpatient Department of the University of Ilorin Teaching Hospital was undertaken over a 5-month period. Data on the mothers' sociodemographic characteristics, and experience of FV and its psychosocial correlates and effects were collected using a semi-structured questionnaire and a 20-item SelfReporting Questionnaire (SRQ) as instruments.

Data analysis. EPI Info version 6 was used to analyse the data.

Results. Sixty-nine mothers (28\%) had experienced FV at the hands of their husbands. Of these women, 49 (71\%) indicated occurrences within the preceding 2 years; in $17(25 \%)$, the violence was severe enough to warrant a hospital visit or treatment. Mothers who experienced FV were significantly more likely to have had previous experiences of violence by an in-law; to have reported child cruelty by a husband; to have children with difficult behaviour; and to have reported that they were neglected by their husbands and not enjoying their marriages. They were also significantly more likely to have a high score on the $S R Q$ and be identified as probable cases with psychological problems (SRQ score $\geq 5)$.
Conclusion. In view of these findings, screening for FV in the primary care setting would be beneficial. Primary care physicians should therefore increase their interest, improve their skill, and carry out more research in the identification and management of FV.

Family violence (FV) is a term used to describe any form of violence against any member of a household or family by one of its members. Usually women and children are the victims and men the perpetrators of $\mathrm{FV}^{1-4}$ Violence in the family is a complex global problem that results from biological, social and cultural factors, as well as having psychological and social consequences. ${ }^{1,3,5,6}$ It cuts across age, race, religion and socio-economic boundaries. ${ }^{1,2,6,7}$

This study focuses on physical assault by men against women with children in a marriage setting - a phenomenon also known as 'wife beating'. 8.9 Emotional and sexual assault were excluded although, in the African setting, these are regrettably still trivialised in the marriage context because of overbearing religious and sociocultural influences, some of which denigrate women. . $^{811}$

In Nigeria, media reports of wife beating and the campaign by women's rights organisations suggest that the problem of family violence exists. Medical data on its extent and consequences are still scanty, however, especially at the crucial primary care level. Globally, 20\% of women experience some form of violence at least once in their lifetime. ${ }^{5}$ A study of 144 women in Sierra Leone reported a wife-beating rate of $66.7 \%,{ }^{12}$ while another in Nigeria, involving 1000 women, reported a rate of approximately $30 \%,{ }^{9}$ and another involving 308 women reported a rate of $78.8 \%{ }^{13}$

Various factors have been found to be associated with increased risk of FV against women. Among these are: age $<35$ years, separated or divorced, low socio-economic status and alcohol abuse. ${ }^{1,9,14,15}$ The socio-economic and educational disadvantages of women, coupled with inequalities imposed by culture, religion, and judicial systems, may be more prevalent in Africa, ${ }^{8-11,13}$ so a higher frequency of $\mathrm{FV}$ can be expected. 
The medical effects of FV are many, and frequent examples include behavioural disorders /anxiety, depression, diagnosable conditions such as acute stress disorders and post-traumatic stress disorders), physical injuries or even death. $1,2,7,11,16$ Children of women affected by violence may also suffer serious psychosocial or physical abuse. 9,17,18

Globally, there is consensus that FV is still under-recognised and under-reported within the medical community. 2, 9,19,20 The reason for this has been adduced to be the negative and neglectful attitude of the medical community towards FV, and to inadequate training in how to recognise and manage it. 19,20 Other reasons that have been suggested are societal misconceptions about FV as a private or criminal matter (rather than medical) and the high tolerance threshold of women towards FV. 2,19,20

Many women attending primary care facilities in Nigeria are known to have psychological problems from diverse causes, among which adverse life events are prominent; ${ }^{21,22}$ the contribution of $\mathrm{FV}$ to this is as yet unknown. Clinical experience also indicates that many women afflicted by FV do not volunteer information without prompting. A simple, short, local screening instrument for eliciting information about FV in a busy outpatient situation will be useful. But the first need is to establish whether the opportunity provided by the primary care setting would be rewarding by ascertaining the extent of the problem, its nature and impact.

Few studies have been done in Nigeria to address FV in the primary care setting, and none to our knowledge in llorin. Our present study therefore adds to the limited literature on reporting the frequency of $\mathrm{FV}$, its correlates and effects. Most importantly, this study could provide a basis for planning initial intervention strategies and for conducting a long-term epidemiological study from which appropriate screening or diagnostic instruments and intervention methods can be developed.

\section{Methods}

This study was a cross-sectional investigation carried out at clinics in the General Outpatient Department (GOPD) of the University of Ilorin Teaching Hospital (UITH) over a 5-month period. The GOPD is essentially a primary care unit since all patients visiting the hospital are seen there first, except for accident and emergency cases.

The study population consisted of 250 mothers from a nonprobability sampling of consecutive married women attending the above clinics who met the inclusion criteria and gave verbal consent to participate. The inclusion criteria for the study were: (i) being currently married and (ii) having at least 1 child $\geq 6$ years old and in school (this factor was used as an inclusion criterion because some questions enquired information on performance of the child at home and at school). Women who were widowed or currently divorced were excluded from recruitment for the sake of uniformity and ease of statistical analysis.

A questionnaire was designed for collecting the sociodemographic data of the mothers and their characteristics in relation to FV. It included questions intended to establish the following: (i) socio-economic characteristics of women and their spouses; (ii) the occurrence of previous physical assault, its frequency and the social context in which it occurred; and (iii) some of its physical and psychosocial effects on the victim and her children.

The $S R Q$ was used to assess psychological disorder in the subjects. The SRQ by Harding et al. ${ }^{23}$ was designed for use in the World Health Organization (WHO) study on strategies for extending mental health care. It was especially designed for screening of psychiatric disturbances in the primary care setting. ${ }^{23}$ The SRQ-1 (or 20-item SRQ) containing nonpsychotic questions was used. Each item in the questionnaire has a score of $\mathrm{O}$ or 1

SRQ-1 was validated in a primary care setting in rural south-western Nigeria and found to effectively discriminate between patients with and without psychiatric morbidity. ${ }^{24}$ This was best done at a cut-off point of 5, which has the optimal sensitivity of $98.8 \%$ and specificity of $90.9 \% .{ }^{24}$ The cut-off point of 5 was also adapted by another study ${ }^{22}$ for assessing the prevalence of psychiatric morbidity among attendees at 5 primary health care centres in 5 towns of a rural local government area in south-western Nigeria.

The Yoruba version of SRQ-1 used by one of the authors (MF) in an earlier study in the same hospital, was used. The two instruments were pilot-tested using 25 mothers at another clinic in Ilorin. The pilot testing revealed that most items on the measures were comprehensible and easy to complete and could be administered within 20 - 25 minutes. Only slight modifications were needed in the semi-structured questionnaire.

Although the instruments were to be self-administered, because of the low level of education among the group, and the need for uniformity, they were read out in private to each of the mothers in the appropriate language by one of the investigators (BA). 
Data analysis was carried out using EPl-info version 6. Simple frequency tables were obtained and chi-square tests were performed to determine significant differences between various variables and correlates. Statistical significance was set at $p \leq 5$.

\section{Results}

A total of 280 mothers who met the inclusion criteria were approached to participate, but only 250 of them gave consent and were assessed; those who declined gave reasons such as lack of time and interest.

Of the 250 mothers, 193 (77\%) were not ill but accompanied their children to the hospital; 29 (12\%) had an acute illness, of whom 18 (7.2\%) had malaria fever, and 28 (11\%) had chronic illnesses such as hypertension and diabetes mellitus, with onset of illness $<2$ months and considered to be stable with no clinical complications.

\section{Demographic characteristics (Table I)}

In terms of age, 210 (84\%) mothers were between 20 and 39 years, while 113 (45\%) husbands were in the same range. The mean age of husbands was 40.7 years ( \pm standard deviation (SD) 7.5), which was significantly higher than that of mothers $(32.3 \pm 6.0)(p=0.000)$. The majority of mothers $(83 \%)$ and their husbands (90\%) had no, or primary school, education and were engaged in unskilled or semiskilled work (71\% of mothers v. $58 \%$ of husbands), indicating a not particularly literate population. Occupation classifications were as follows:

- skilled - professionals with or without university degrees, and senior and intermediate civil servants

- semi-skilled - artisans, junior civil servants and drivers

- unskilled - labourers, petty traders, uneducated, unemployed and housewives.

The Yoruba ethnic group constituted about $83 \%$ of mothers and husbands las expected by the study's location in a Yoruba-speaking town). Christianity was practised by $43 \%$ of the sample, while $57 \%$ practised Islam.

Two hundred and nine (84\%) mothers had at least 1 male child, and 202 (81\%) had <5 children; 98\% were living with their husband in the same household; 19 (8\%) had had a previous marriage; 123 (49\%) had been married > 10 years, and $76 \%$ were in monogamous marriages. Only 10\% of husbands consumed alcohol.

\section{Family violence characteristics}

Sixty-nine (28\%) mothers reported having been beaten by their husbands; $49(71 \%$ - 49/69) of these women reported that the beating occurred within 2 years of the study, and $17(51 \%$ - 17/49) indicated a frequency of more than twice within the same period. Among the 69 mothers who had experienced FV, 17 (25\% - 17/49) indicated that the injuries received were severe enough to warrant a hospital visit and treatment.

\section{Correlates of FV (Tables I and II)}

Mothers who had been beaten previously by their husbands were compared with those who had never been. The group that had experienced FV previously was found to be significantly more likely to report the following: (i) to have husbands of low educational (s primary education) and occupational ( $\leq$ semi-skilled) levels; (ii) to be in marriages $\geq 10$ years' duration; (iii) to have $\geq 5$ children; (iv) to have husbands with a previous history of divorce; $(v)$ that their husbands had behavioural problems or were neglectful; (vi) episodes of child cruelty by husbands; (vii) previous experiences of FV caused by an in-law; or (viii) having an in-law living with them.

There was, however, no correlation between FV and the following: (i) age of the mother or her husband; (ii) mother's educational and occupational levels; (iii) type of family or marriage; (iv) absence of a male child; and ( $v$ ) alcohol use by husband.

\section{Impact of FV (Tables II and III)}

Mothers who had experienced FV previously were significantly more likely to score higher on the SRQ and be identified as probable cases with psychological problems $I S R Q$ score $\geq 51$. Of the 69 mothers who experienced FV, $28141 \%-$ $28 / 69)$ had an SRQ score $\geq 5$, compared with the 30 without FV experience (17\% - 30/181) ( $<<0.000)$. These figures suggest that FV probably contributed to psychological problems in these mothers. Also, the mean SRQ score of mothers (4.2 \pm 2.8 ) who had experienced FV previously was significantly higher than those who had never experienced it $(2.2 \pm 8.0)(p<0.000)$.

In addition, victims of FV were significantly more likely to have children who were under-achieving at school, and with difficult behaviour or bed-wetting after 7 years of age. FV also adversely affected marriages: of the 17 women who indicated that they were not enjoying their marriages, 10 (59\%) had experienced FV. 


\begin{tabular}{|c|c|c|c|c|c|c|}
\hline \multirow[b]{2}{*}{ Variables } & & \multicolumn{2}{|c|}{$\begin{array}{l}\text { Had FV incidents } \\
\qquad\left(N_{1}=69\right)\end{array}$} & \multicolumn{2}{|c|}{$\begin{array}{l}\text { No FV incidents } \\
\qquad\left(\mathrm{N}_{2}=181\right)\end{array}$} & \multirow{2}{*}{$\begin{array}{l}\text { Significance } \\
\text { (p-value) }\end{array}$} \\
\hline & & $n_{1}$ & (\%) & $\mathrm{n}_{2}$ & (\%) & \\
\hline \multirow[t]{4}{*}{ Mothers' age group (yrs) } & $<20$ & 1 & $(2)$ & 0 & (0) & 0.075 \\
\hline & $20-29$ & 16 & (23) & 62 & (34) & \\
\hline & $30-39$ & 37 & $(54)$ & 95 & (53) & \\
\hline & $\geq 40$ & 15 & $(22)$ & 24 & (13) & \\
\hline \multirow[t]{4}{*}{ Mothers' education } & None & 12 & (17) & 30 & (17) & 0.062 \\
\hline & Primary & 23 & (33) & 34 & (19) & \\
\hline & Secondary & 21 & (30) & 62 & (34) & \\
\hline & Tertiary & 13 & (19) & 55 & (30) & \\
\hline \multirow[t]{3}{*}{ Mothers' occupational group } & Skilled & 13 & (19) & 59 & (33) & 0.092 \\
\hline & Semi-skilled & 9 & (13) & 17 & (9) & \\
\hline & Unskilled & 47 & (68) & 105 & (58) & \\
\hline \multirow[t]{4}{*}{ Husbands' age group (yrs) } & $\leq 29$ & 1 & (2) & 4 & (2) & 0.135 \\
\hline & $30-39$ & 26 & (38) & 82 & $(45)$ & \\
\hline & $40-49$ & 27 & (39) & 76 & $(42)$ & \\
\hline & $\geq 50$ & 15 & $(22)$ & 19 & (11) & \\
\hline \multirow[t]{4}{*}{ Husbands' education } & None & 8 & (12) & 18 & (10) & 0.000 \\
\hline & Primary & 24 & (35) & 20 & (11) & \\
\hline & Secondary & 16 & (23) & 62 & (34) & \\
\hline & Tertiary & 21 & (30) & 81 & $(45)$ & \\
\hline \multirow[t]{3}{*}{ Husbands' occupational group } & Skilled & 19 & $(28)$ & 88 & (49) & 0.007 \\
\hline & Semi-skilled & 13 & (19) & 31 & (17) & \\
\hline & Unskilled & 37 & (39) & 62 & (34) & \\
\hline \multirow[t]{2}{*}{ Type of family } & Monogamy & 50 & (73) & 141 & (78) & 0.460 \\
\hline & Polygamy & 19 & $(28)$ & 40 & (22) & \\
\hline \multirow[t]{3}{*}{ Husbands' no. of wives } & 1 & 49 & (71) & 143 & (79) & 0.104 \\
\hline & 2 & 14 & (20) & 33 & (18) & \\
\hline & $>2$ & 6 & (9) & 5 & (3) & \\
\hline \multicolumn{2}{|c|}{ Duration of mothers marriage (yrs) $\leq 10$} & 18 & $(26)$ & 109 & $(60)$ & 0.000 \\
\hline & $\geq 11$ & 51 & (74) & 72 & $(40)$ & \\
\hline \multirow[t]{2}{*}{ Husbands' no. of divorce } & None & 52 & $(75)$ & 162 & (90) & 0.008 \\
\hline & $\geq 1$ & 17 & $(25)$ & 19 & (10) & \\
\hline \multirow[t]{2}{*}{ No. of children of mother } & $\leq 4$ & 51 & (74) & 151 & (83) & 0.127 \\
\hline & $\geq 5$ & 18 & $(26)$ & 30 & (17) & \\
\hline \multirow[t]{2}{*}{ Alcohol use by husbands } & Yes & 11 & (16) & 13 & (7) & 0.063 \\
\hline & No & 58 & (84) & 168 & (93) & \\
\hline \multirow[t]{2}{*}{ Living with in-laws } & No & 35 & (51) & 119 & $(66)$ & 0.042 \\
\hline & Yes & 34 & (49) & 62 & (34) & \\
\hline \multirow[t]{3}{*}{ No. of mothers' male children } & 0 & 13 & (19) & 28 & (16) & 0.441 \\
\hline & 1 & 19 & $(28)$ & 65 & (36) & \\
\hline & $\geq 2$ & 37 & (54) & 88 & (49) & \\
\hline
\end{tabular}




\begin{tabular}{|c|c|c|c|c|c|}
\hline \multirow[b]{2}{*}{ Variables } & \multicolumn{2}{|c|}{ Had FV incidents $\left(N_{1}=69\right)$} & \multicolumn{2}{|c|}{ No FV incidents $\left(\mathrm{N}_{2}=181\right)$} & \multirow{2}{*}{$\begin{array}{l}\text { Sign. level } \\
\text { ( } p \text {-value) }\end{array}$} \\
\hline & $\mathrm{n}_{1}$ & $(\%)$ & $\mathrm{n}_{2}$ & (\%) & \\
\hline \multicolumn{6}{|c|}{ FV by husband's relatives } \\
\hline Yes & 7 & (10) & 2 & (1) & \multirow{2}{*}{0.002} \\
\hline No & 62 & (90) & 179 & (99) & \\
\hline \multicolumn{6}{|c|}{ Child cruelty by husband } \\
\hline Yes & 8 & (12) & 8 & $(44)$ & \multirow[t]{2}{*}{0.047} \\
\hline No & 61 & (88) & 173 & (96) & \\
\hline \multicolumn{6}{|c|}{ At least one child under-achieving at school } \\
\hline Yes & 21 & (30) & 28 & $(16)$ & \multirow[t]{2}{*}{0.013} \\
\hline None & 48 & (70) & 153 & (85) & \\
\hline \multicolumn{6}{|c|}{ At least one child with a difficult behaviour } \\
\hline Yes & 31 & $(45)$ & 42 & $(23)$ & \multirow[t]{2}{*}{0.001} \\
\hline None & 38 & (55) & 139 & $(77)$ & \\
\hline \multicolumn{6}{|c|}{$\begin{array}{l}\text { At least one child who was still bedwetting } \\
\text { after age } \geq 7 \text { years }\end{array}$} \\
\hline Yes & 26 & (38) & 31 & (17) & \multirow[t]{2}{*}{0.015} \\
\hline No & 53 & (62) & 140 & (77) & \\
\hline \multicolumn{6}{|c|}{ Earning more income than husband } \\
\hline Yes & 9 & $(13)$ & 15 & (8) & \multirow[t]{2}{*}{0.368} \\
\hline No & 60 & (87) & 166 & (92) & \\
\hline \multicolumn{6}{|c|}{ Husband has a behavioural problem } \\
\hline Yes & 21 & (30) & 9 & (5) & \multirow[t]{2}{*}{0.000} \\
\hline No & 48 & (70) & 172 & (95) & \\
\hline \multicolumn{6}{|c|}{ Feel neglected by husband } \\
\hline Yes & 10 & (15) & 9 & (5) & \multirow[t]{2}{*}{0.023} \\
\hline No & 59 & (86) & 172 & (95) & \\
\hline \multicolumn{6}{|c|}{ Not enjoying marriage } \\
\hline Yes & 10 & (15) & 7 & (4) & \multirow[t]{2}{*}{0.008} \\
\hline No & 59 & (86) & 174 & (96) & \\
\hline \multicolumn{6}{|c|}{ Total SRQ score } \\
\hline$<5$ & 41 & (59) & 151 & (83) & \multirow[t]{2}{*}{0.000} \\
\hline$\geq 5$ & 28 & (41) & 30 & (17) & \\
\hline \multicolumn{6}{|c|}{$\begin{array}{l}N=\text { total number of mothers in the study population }=250 N_{1}=\text { total number of mothers who reported at least one incidence of family violence } N_{2}=\text { total number } \\
\text { mothers who reported no incidence of family violence. } \\
n_{1} \text { and } n_{2} \text { are the percentages of } N_{1} \text { and } N_{2} \text { respectively to the nearest whole number. }\end{array}$} \\
\hline
\end{tabular}

When the symptom profile from the $S R Q$ was assessed, it was observed that the symptoms that were significantly reported by mothers who had experienced FV over those who had not included: (i) poor appetite; (ii) easily frightened; (iii) feel nervous, tense or worried; (iv) difficulty in thinking clearly; (v) feel unhappy; (vi) crying more than usual; (vii) finding it difficult to enjoy daily activities; (viii) daily work suffering as a result of illness; (ix) feel worthless; $(x)$ lost interest in things; $(x i)$ thoughts of ending life; and (xii) feel tired all the time.

The balance of these symptoms suggests depression, meaning that victims of FV were significantly likely to report depressive symptoms. However, despite the fact that 53 mothers reported being unhappy, only 12 reported suicidal ideation, suggesting that the depressive symptoms were most probably mild or moderate.

\section{Discussion}

With a prevalence rate of $28 \%$ in this study (that was restricted to physical violence and a specific group of women), family violence is probably more common in primary care settings in Nigeria than is realised. Primary care practice provides a setting that offers better scope for women to discuss issues such as FV. It is time to take advantage of this opportunity, by way of primary care providers carrying out assessment, intervention and/or appropriate referral of women in violent relationships.

Compared with two other studies in Nigeria ${ }^{9,13}$ and some in Africa, ${ }^{10,12}$ the prevalence rate of $\mathrm{FV}$ in this study is relatively low. The reason may lie in the fact that this study was restricted (as described above), as well as its hospital and urban base, with possible cultural differences possibly also contributing. 


\begin{tabular}{|c|c|c|c|c|c|}
\hline \multirow[b]{2}{*}{ Variables } & \multicolumn{2}{|c|}{$\begin{array}{l}\text { Mothers with FV } \\
\text { reports }\left(N_{1}=69\right)\end{array}$} & \multicolumn{2}{|c|}{$\begin{array}{l}\text { Mothers without FV } \\
\text { reports }\left(\mathrm{N}_{2}=181\right)\end{array}$} & \multirow{2}{*}{$\begin{array}{l}\text { Level of } \\
\text { significance } \\
\text { (p) }\end{array}$} \\
\hline & $\mathrm{n}_{1}$ & $(\%)$ & $\mathrm{n}_{2}$ & (\%) & \\
\hline 1. Do you often have headaches? & 40 & (58) & 61 & (34) & 0.000 \\
\hline 2. Is your appetite poor? & 13 & (19) & 14 & (8) & 0.021 \\
\hline 3. Do you sleep badly? & 15 & (22) & 26 & (14) & 0.224 \\
\hline 4. Do you feel easily frightened? & 38 & (55) & 58 & (32) & 0.001 \\
\hline 5. Do your hands shake? & 14 & (20) & 20 & (11) & 0.089 \\
\hline 6. Do you feel nervous, tense or worried? & 34 & (49) & 57 & (32) & 0.014 \\
\hline 7. Is your digestion poor? & 0 & (0) & 6 & (3) & 0.192 \\
\hline 8. Do you have trouble thinking clearly? & 6 & (9) & 4 & (2) & 0.029 \\
\hline 9. Do you feel unhappy? & 28 & (41) & 25 & (14) & 0.000 \\
\hline 10. Do you cry more than usual? & 22 & (32) & 18 & (10) & 0.000 \\
\hline 11. Do you find it difficult to enjoy your daily activities? & 9 & (13) & 8 & (4) & 0.023 \\
\hline 12. Do you find it difficult to make decisions? & 2 & (3) & 7 & (4) & 1.000 \\
\hline 13. Is your daily work suffering as a result of illness? & 6 & (9) & 2 & (1) & 0.006 \\
\hline 14. Do you feel unable to play a useful part in life? & 2 & (3) & 6 & (3) & 1.000 \\
\hline 15. Do you feel that you are a worthless person? & 2 & (3) & 6 & (3) & 1.000 \\
\hline 16. Have you lost interest in things? & 13 & (19) & 15 & (8) & 0.032 \\
\hline 17. Has the thought of ending your life been in your mind? & 9 & (13) & 3 & (2) & 0.000 \\
\hline 18. Do you feel tired all the time? & 16 & (23) & 22 & (12) & 0.048 \\
\hline 19. Do you have uncomfortable feelings in your stomach? & 5 & (7) & 12 & (7) & 1.000 \\
\hline 20. Are you easily tired? & 17 & (25) & 27 & (15) & 0.106 \\
\hline \multicolumn{6}{|c|}{$\begin{array}{l}N \text { is the total number of people in the study population }=250 \text {. } \\
N_{1} \text { is the total number of mothers who reported at least one incidence of family violence. } \\
N_{2} \text { is the total number of mothers who reported no incidence of family violence. } \\
n_{1} \text { and } n_{2} \text { are the percentages of } N_{1} \text { and } N_{2} \text { respectively to the nearest whole number. }\end{array}$} \\
\hline
\end{tabular}

In terms of correlates, socio-economic status as measured by mothers' educational and occupational levels did not influence the occurrence of FV in this study. This is consistent with the pattern observed in Sierra Leone ${ }^{12}$ but contradicts some other studies. ${ }^{2,9}$ However, husbands with low educational (s primary education) and occupational (s semi-skilled) levels were more likely to beat their wives. This suggests an inverse relationship between these factors and $\mathrm{FV}$, which is consistent with the pattern in a previous study in Nigeria. ${ }^{9}$ Husbands indicted as neglectful, behaviourally disturbed or childabusing in this study were also likely to be 'wife-beaters'. This pattern probably suggests progressively dysfunctional family situations.

Family structure and formation factors were found to influence $\mathrm{FV}$ in this study. For example, victims of FV were more likely to: (i) have $\geq 5$ children, (ii) have experienced in-lawrelated violence; or (iii) be living with an in-law. Based on the prevailing sociocultural environment, it is reasonable to expect this type of family structure or formation in lower socio-economic groups, where it is possible for husbands to be 'culture respecting' enough to permit family members to physically abuse their wives.
Despite strong evidence in many studies 1,9,14 linking substance abuse (especially alcohol) to FV, it was found not to be influential in this study. The small size of our study was probably a major factor; a larger study would be necessary to fully explore the relationship of this variable with FV in the primary care setting.

The consistent global pattern of adverse physical and psychosocial effects of FV on mothers $2,9,13,15,16$ is also supported by this study. A substantial number of mothers $125 \%$ - 17/69) suffered injuries severe enough to seek medical attention. In addition, a significant number of mothers who had experienced FV were identified as probably having psychological problems by the SRQ instrument $141 \%$ $28 / 691$. When this figure is compared with that of $28 \%$ found in mothers of children with sickle cell disease by the same instrument in the same setting as this one, ${ }^{25}$ the severity of the psychological distress of FV can be better recognised. Furthermore, as part of a complex family disorder, the children of victims also suffered. They were more likely to be underachieving at school, to have behavioural problems and be bedwetting after 7 years of age. 
In order to identify, manage or prevent FV, a holistic or 'biopsycho-social' approach to health care ${ }^{26}$ by primary care practitioners is crucial. While public education, aimed at men, on the harmful effects of FV is a good strategy, husbands of victims should be invited for counselling and education in every case of FV. Children of victims should also be assessed for physical and psychosocial problems. ${ }^{27}$

One of the major limitations of this study was its restriction to only physical violence - to the exclusion of emotional, verbal and sexual violence. It was additionally restricted to currently married mothers with children $\geq 6$ years attending the outpatient department only, excluding mothers from the emergency and other departments. All this put a limit on its generalisability and applicability. Considering that it is a preliminary study, opportunity still exists in the future to improve these defects.

The tertiary hospital and urban-based nature of the study, although carried out in a primary care setting, may also restrict the application of its findings to the wider community - especially rural areas - where the level of health care and socio-economic status are likely to be very different.

\section{Conclusion}

This study has provided evidence that women at primary care level in Nigeria not only experience FV but that it also negatively affects their physical and psychosocial well-being and that of their children. Unless primary care providers take interest in the psychosocial care of these victims, the majority of them will continue to suffer in silence.

Moreover, based on the findings of this study, it can be reasonably concluded that screening for $\mathrm{FV}$ in primary care settings in Nigeria would be rewarding, with potential for improving women's health. We therefore recommend that primary care physicians increase their interest, knowledge, skill and research in the practicable and affordable identification and management of family violence.

\section{References}

1. Schwab لI. Spouse abuse: medical and psychiatric perspectives. Int Psych Today 1998; 8(1): 5-12

2. Council on Ethical and Judicial Affairs, American Medical Association. Physicians and Domestic Violence: Ethical Considerations. JAMA 1992; 267(23): $3190-3193$.

3. Moreno CG. World Health Organisation recommendations put women first. Lancet 1999; 354: 2075-2076

4. Datner EM, Ferroggiaro AA. Violence during pregnancy. Emerg Med Clin North Am 1999: 17(3): 645-655.

5. Haile-Mariam T, Smith J. Domestic violence against women in the international community. Emerg Med Clin North Am 1999; 17(3): 617-630.

6. World Health Organization. World Report on Violence and Health: Summary. Geneva: WHO, 2002: 13-23

7. Eisenstat SA, Bancroft L. Domestic violence. N Engl J Med 1999; 341 (12): 886 892.

8. Hindin MJ. Understanding women's attitudes towards wife beating in Zimbabwe. Bull World Health Organ 2003; 81 (7): 501-508.

9. Odujinrin O. Wife battering in Nigeria. Int J Gynecol Obstet 1993: 41: 159-164.

10. Hof C, Richters A. Exploring intersections between teenage pregnancy and gender violence: lessons from Zimbabwe. Afr J Reprod Health 1999; 3(1): 51-65.

11. Esen UJ. Violence against women in developing countries (Letter to the Editor ). East Afr Med J 2000; 77: 400.

12. Coker AL, Richter DL. Violence against women in Sierra Leone: frequency and correlates of intimate partner violence and forced sexual intercourse. Afr J Reprod Health 1998; 2(1): 61-72.

13. Okemgbo CN, Omideyi AK, Odimegwu CO. Prevalence, patterns and correlates of domestic violence in selected Igbo communities of Imo state, Nigeria. Afr J Reprod Health 2002: 6(2): 101-14.

14. Atwood JD. Domestic violence: The role of alcohol (Letter to the Editor). JAMA 1991; 265(4): 460-461.

15. Haywood YC, Haile-Marian T. Violence against women. Emerg Med Clin North Am 1999; 17(3): 603-615

16. Council on Scientific Affairs, American Medical Association. Violence against women relevance for medical practitioners. JAMA 1992; 267(23): 3184-3189.

17. Siegel RM, Hill TD, Henderson VA, et al. Screening for domestic violence in the community paediatric setting. Paediatrics 1999; 104(4): 874-877.

18. Pakier RA, Leneghan PA, Muelleman RL. Battered women: where they go for help. J Emerg Nursing 1998; 24: 16-19.

19. Rodriquez MA, Bauer HM, Mcloughlin E, Grumbach K. Screening and intervention for intimate partner abuse; practices and attitudes of primary care physicians. JAMA 1999; 282(5): 468-474

20. Sugg NK, Inui T. Primary care physicians' response to domestic violence - opening a Pandora's box. JAMA 1992; 267(23): $3157-3160$

21 . Abiodun $O A$. Psychiatry morbidity in a primary health care centre in a rural community in Nigeria. Cent Afr J Med 1989; 34(4): 372-377.

22. Ohaeri JU, Odejide OA, Gureje O, Olatawura MO. The prevalence of psychiatric morbidity among adults attending at five primary health care facilities of a rural community in Nigeria. Nigerian Postgrad Med J 1994; 1(1): 12-16.

23. Harding TW, De Arango MV, Baltazar J, et al. Mental disorders in primary health care: a study of their frequency and diagnosis in four developing countries. Psychol Med 1980, 10: 231-241.

24. Abiodun OA. Sensitivity and validity of the Self-Reporting Questionnaire (SRQ) in a primary health care centre in a rural community in Nigeria. Psychopathologie Africaine 1988-1989; XXIII 1): 79-88

25. Tunde-Ayinmode MF. Psychosocial impact of sickle cell disease on children and their mothers in University of Ilorin Teaching Hospital: a controlled study. Dissertation, Faculty of Psychiatry, National Postgraduate Medical College of Nigeria, 1999. FMC Psych dissertation, National Postgraduate Medical College of Nigeria, Lagos, 1999.

26. Abiodun OA. The need for a holistic approach to patient care. Postgrad Doctor Afr 13(4): 95-97.

27. Adelekan ML. Psychiatric disorders of children and young adults in developing countries. In: Tantam D, Appleby L, Duncan A, eds. Psychiatry for the Developing World. London: Gaskell Press (Imprint of the Royal College of Psychiatrists), 1995: $311-340$. 